\title{
Thousand Organisms
}

National Cancer Institute

\section{Source}

National Cancer Institute. Thousand Organisms. NCI Thesaurus. Code C71187.

A unit of measure of quantity of organisms expressed in thousands. 